\title{
LAS GARANTIAS PERSONALES EN DERECHO ROMANO JUSTINIANEO
}

VICTORIANO SAIZ LOPEZ

\section{1.- Planteamiento general.}

En el estudio de la evolución de las garantías personales en el derecho romano justinianeo, las conclusiones a que ha llegado ASTUTI, en torno a la relación existente entre stipulatio y constitutum debiti alieni, basadas en la constitución reformadora $\mathrm{CJ} 4,18,2$, son, a nuestro juicio, especialmente relevantes a la hora de plantear el problema de los criterios seguidos por los compiladores.

Con posterioridad, los estudios de autores como FREZZA y particularmente ARCHI, sobre el discutible alcance práctico de la revisión bizantina de las antiguas fuentes romanas, han venido a enriquecer una polémica doctrinal que se inserta en otra más amplia referida a los criterios que presidieron la elaboración del Corpus Iuris.

Recientemente, el Profesor DIAZ BAUTISTA ha puesto de actualidad nuestro tema con su trabajo sobre las instituciones de garantía bancaria en la legislación de Justiniano.

La aportación que pretendemos hacer aquí consiste fundamentalmente en una síntesis de las diversas posiciones doctrinales y en el desarrollo de una interpretación de CJ 4, 18, 2 que plantea cuál ha podido ser el destino final de las instituciones romanas en la vida efectiva del Derecho en la parte oriental del Imperio.

La constitución de Justiniano del año 531 nos presenta la abolición del receptum argentariorum, que ha caído en desuso, en relación con el constitutum debiti (1).

Recepticia actione cessante quae sollemnibus verbis composita inusitato recessit vestigio, necessarium nobis visum est magis pecuniae constitutae naturam ampliare (C. $4,18,2$ ).

Después de ampliar el ámbito de aplicación de la a. pec. const., Justiniano insiste en el principio de que el constitutum debe tener una deuda como presupuesto objetivo para su validez, justificando la abolición de la recepticia, precisamente, por lo absurdo e inicuo de la abstracción que caracterizaría a este instituto.

...ita tamen, ut hoc ei inhaereat, ut pro debito fiat constitutum (cum secundum antiquam recepticiam actionem exigebatur et si quid non fuerat debitum), cum satis absurdum et tam nostris temporibus quam iustis legibus contrarium est permittere per actionem recepticiam res indebitas consequi...

En las Instituciones encontramos una explicación de la reforma en términos muy parecidos. (I. 4, 6, 8). 
...de pecunia constituta, cui similis videbatur recepticia: sed ex nostra consititutione (cum et, si quid plenius habebat, hoc in pecuniam constitutam transfusum est) et ea, quasi supervacua, iussa est cum sua auctoritate a nostris legibus recedere (2).

Según sabemos, como consecuencia de esta abolición, los compiladores omitieron en el Digesto un título correspondiente a la cláusula del Edicto del Pretor relativa al receptum argentariorum, borrando toda huella de este instituto en la compilación, insertando bajo la rúbrica de pec. const. y en otras partes, con las debidas modificaciones, algunos textos clásicos que originariamente se referían al receptum.

En general, se ha interpretado lo anterior como una fusión de ambas instituciones y como una ampliación del constitutum en relación con la abolición del receptum (3).

Igualmente, de acuerdo con los datos que Justiniano suministra, se ha llegado a admitir una gran afinidad entre las dos instituciones (4).

En esta dirección, aunque admitamos que función económica del receptum es la de una apertura de crédito, ya que opera con independencia de que el cliente tenga $o$ no fondos depositados en poder del banquero, también podemos considerar como muy probable que el banquero, asumiendo la deuda de otra persona, normalmente, tendrá en su poder fondos depositados por ésta; por tanto, el banquero es deudor del cliente respecto de estas cantidades. De este modo, el receptum puede ser equiparado no sólo al c. d. alieni, como se viene considerando en general, teniendo en cuenta, exclusivamente, la relación jurídica entre el cliente y el tercer acreedor, sino que también el receptum puede ser equiparado al mismo c. debiti proprii. Esto es así, si nos fijamos en la relación jurídica existente entre el banquero depositario y su cliente.

Esta doble función económica que cumple el receptum se concreta del siguiente modo:

1.- Aceptación ex recepto ordinaria, por parte del banquero, de la responsabilidad derivada de una deuda de su cliente. En este caso estamos ante una apertura de crédito.

2.- Aceptación ex recepto, por parte del banquero depositario de fondos del cliente, de la responsabilidad derivada de una deuda del mismo, con lo que el banquero ejecuta pagos a cuenta del cliente, cumpliendo su obligación de restituir propia de un depositario. Aquí, el banquero actúa como administrador de un patrimonio ajeno y cumple la función de intermediario en los pagos, facilitándolos al evitar los inconvenientes del intercambio material de numerario. $Y$, lo que es muy importante, puede contribuir a incrementar los medios de pago en función del desarrollo económico, mediante la concesión del crédito.

La bipolaridad a que nos acabamos de referir puede estar en paralelo con la función y desarrollo histórico del constitutum, lo que podría explicar el destino final convergente de ambas instituciones (5).

También se considera la existencia de una contradicción en relación con los motivos que alega Justiniano en materia de abolición del receptum. Así, se habla, 
en primer lugar, de la caída en desuso del receptum, es decir, de la acción antigua de la que se borra toda huella del Digesto (6); pero resulta soprendente que la no utilización del receptum pueda servir de justificación de la necesidad de ampliar el constitutum, siendo inadmisible un absurdo intento de perpetuar o, mejor dicho, de hacer revivir las reglas características de una institución abandonada en la práctica. Además, lo que venimos diciendo contrasta con lo que dispone nuestra constitución, en estos términos:

His videlicet, quae argenti distractores et alii negotiatores indefense constituerint, in sua firmitate secundum morem usque adhuc obtinentem durantibus.

Se ha venido entendiendo que aquí estaríamos ante una disposición transitoria, una cláusula de derecho intertemporal aplicable a los recepta concluidos por los banqueros con anterioridad a la entrada en vigor de la reforma (7). Pero, esta interpretación choca frontalmente con el dato relativo a la caída en desuso del receptum. No es necesaria una norma transitoria para un negocio que no vincula a los banqueros (8).

En esta dirección, considerando la hipótesis según la cual el receptum argentariorum habría tenido su continuación en la promissio de los banqueros en el derecho comercial medieval (9), se llega a mantener que el receptum ha permanecido en Occidente, y especialmente en Italia, mientras que en Oriente la no recepción del instituto habría sido la causa verdadera de la constitución reformadora de Justiniano. El motivo de esta no recepción se encontraría en el hecho de que el receptum tenía un correspondiente en su función económica y en su estructura jurídica en el derecho griego. En Oriente no se habría practicado el receptum, tal y como era conocido por los romanos, al existir alli un instituto propio que cubre las mismas necesidades. Así, la reforma justinianea se habría limitado a recoger la persistencia de esta tradición jurídica helenística. Los compiladores encuentran el receptum en los escritos de los clásicos pero no en la práctica de su tiempo y, no conociendo su historia ni el derecho en Occidente, habrian caído en un comprensible error, creyendo de buena fe que el instituto estaba en desuso. La pretendida disposición transitoria vendría referida no al receptum sino al constitutum debiti (10).

Sin embargo, la hipótesis anterior suscita más de una razón de duda. Por lo que se refiere a la persistencia del receptum argentariorum en las regiones occidentales del Imperio, podemos decir que constituye una premisa que está todavía por demostrar, pues se basa en fundamentos muy inciertos. En cuanto a la adhesión a la hipótesis de la no recepción en Oriente, sin duda, es cierto que el mundo de los negocios de los "argentarios" romanos estaba organizado a imitación del mundo de los "trapezitas" griegos. Se puede hablar de asimilación de los institutos y de los esquemas negociales, entre los que hay que incluir el receptum. En efecto, puede parecer probable la no recepción de un instituto que el derecho romano había tomado prestado del derecho griego. Es inverosímil que la expansión imperial de Roma haya podido ofrecer a la práctica de las regiones de Oriente algo nuevo e influir en el desarrollo de un tráfico bancario muy evolucionado que habia llegado a generalizarse en todo el mundo antiguo. 
Ahora bien, entendemos que el receptum viene enmarcado dentro de la órbita jurídica del derecho romano y obedece a unas necesidades históricas muy concretas $\mathrm{y}$, aunque pretenda acoger los principios del modelo griego, no por ello puede desconocerse la originalidad de la institución. En definitiva, hemos de reconocer que en este campo no se halla plenamente desvelada la incertidumbre en lo referente a la afinidad jurídica entre las figuras negociales del tráfico bancario griego y el receptum argentariorum (11).

Aun cuando no aceptemos la hipótesis de la no recepción, lo que parece indudable es que nuestro instituto es desconocido y no utilizado en la práctica justinianea. Puede haber dudas en cuanto a los motivos, pero no en relación al hecho mismo de que la acción recepticia pertenece al pasado.

En efecto, partimos de que el receptum argentariorum es desconocido en la práctica de la época de Justiniano (12). No se podría objetar que mal se entiende la abolición legislativa de una institución condenada inapelablemente al olvido, puesto que, es comprensible que Justiniano, al encontrarse ante una reliquia de la jurisprudencia clásica en los comentarios ad edictum, considerase oportuna una expresa derogación de aquellas normas, lo que, ocasionalmente, llevó a cabo en la misma constitución en que reformaba el constitutum.

A esta conclusión parece oponerse la disposición ya conocida que, según la opinión común, constituiría una disposición transitoria relativa al receptum. Pero, si esta opinión común es cierta habría que atribuir a Justiniano no sólo una falsa noticia sino también una inadmisible contradicción. Puede dudarse de ciertas afirmaciones de los bizantinos, pero con mayor cautela deben acogerse otro tipo de noticias que no pueden ser rechazadas sin graves motivos, como ocurre con ésta. Cuando Justiniano se refiere al desuso del receptum, nada impone al emperador afirmar una cosa falsa, lo que todos habrían podido constatar. Tampoco sería admisible declarar insusitado un negocio y, al mismo tiempo, emanar una norma transitoria apelando al mos usque adhuc obtinens. Pero hay más; en esta disposición se usa la expresión indefense constituere, cuando no hay razón para no recurrir al término técnico recipere, como en los parágrafos precedentes, máxime si tenemos en cuenta que se refiere a los argenti distractores et alii negotiatores, siendo el receptum el negocio propio de los argentarii. Resulta también extraño que donde el emperador debía haber confirmado la validez de los recepta, concluidos con anterioridad a la reforma, haga referencia al mos usque adhuc obtinens.

Es posible que, con estas palabras, Justiniano no se haya referido al receptum. Tampoco se referiría al normal constitutum pro alio sino a las promesas con las que, según sus usos, banqueros y mercaderes se obligaban a pagar indefense. Promesas que pueden reconducirse al concepto general de constituere de mayor amplitud que el constituere clásico. Que en la práctica del mundo bancario helenístico se encontrasen en uso formas de garantía diversas del constitutum romano, que no podamos identificar entre ellas al receptum argentariorum, aunque a éste puedan parecer afines, y que su régimen jurídico venga referido en las fuentes justinianeas al constitutum debidamente transformado, bajo el nombre genérico de "antiphonesis", aparece, seguramente confirmado, para el período imnediatamente sucesi- 
vo al 531, por otras fuentes, entre las que podemos citar la Nov. IV, Nov. CXVI c. 6, Nov. CXXXVI, Ed. VII y Ed. IX de Justiniano (13).

En virtud de los textos posteriores a la reforma del 531, el constitutum -antiphonesis- de los argentarii vendría, ordinariamente, asumido sin las limitaciones de la responsabilidad del promitente pro alio que propias del derecho común. Para probar que esto es así, recurrimos a los dos pricipios siguientes:

1.- El referente al beneficium excussionis.

2.- El carácter riguroso de la obligación bancaria, con arreglo a la terminología indefense constituere.

El primer tema que se nos plantea es el de determinar al alcance del beneficium excussionis. En la novela CXXXVI, Justiniano modifica lo dispuesto en la Novela IV en la cual declaraba (cap. 3, p.1) no ser admitidos los banqueros al beneficium ordinis seu excussionis, ahora introducido. La corporación de los baqueros habría presentado una protesta, seguramente por medio del comes sacrarum largitionum strategius, al que el emperador dirige en contestación la Novela CXXXVI. Los banqueros, con esta Novela, son admitidos a pactar, en su favor, la renuncia al beneficio de excusión cuando hayan dado dinero a título de mutuo, recibiendo garantes del mutuatario. De este modo, Justiniano da acogida a una de las dos alternativas contenidas en la protesta de la corporación bancaria: o la extensión a los contratos en que los banqueros son deudores (garantes) del beneficio de la Novela IV (benef. ordinis seu excussionis), o la exclusión de los contratos en que los banqueros son acreedores (y han recibido garantes) del beneficio de la Novela IV (14).

En el segundo punto, consideramos la costumbre de los banqueros de renunciar, convencionalmente, a las ventajas del derecho común en la garantía de la obligaciones; parece seguro que, después de haber condenado en C. 4, 18, 2 la recepción de obligaciones abstractas y de haber remachado el principio según el cual el constitutum debe tener siempre como presupuesto una deuda, Justiniano considera oportuno excluir la aplicación de estos principios a la conocida antiphonesis que los banqueros y comerciantes hayan contraído indefense, respetando, al menos en vía transitoria, los usos comerciales de su tiempo (15).

Esta interpretación concuerda con el sentido del término indefense constituere, sobre el que tanto se ha escrito desde los glosadores (16).

Tradicionalmente, se viene entendiendo que el término serviría para indicar ut nulla exceptione se tueri possint, sine ulla defensione, vel exceptione (17).

Considerando lo anteriormente establecido, el indefense constituere puede ser, solamente, la fórmula que contiene la situación jurídica de quien ha asumido un vínculo obligatorio de carácter abstracto que debe cumplir sin poder oponer excepciones (18).

En defintiva, que el receptum argentariorum es para Justiniano un instituto del pasado y mal conocido, aparece claro si se tienen en cuenta las fórmulas vagas y equívocas con que viene caracterizado: por ejemplo, las palabras sollemnibus verbis composita, sobre las que tanto se ha discutido, plantean el problema relativo a si califican al negocio, a la acción o al libelo. Es difícil buscar una solución satisfacto- 
ria a este interrogante; probablemente, con esta expresión se ha querido apoyar la afirmación del desuso del instituto, recurriendo a su hipotético formalismo. A atribuir carácter formal al receptum también pudo contribuir la presencia de un término puramente romano como recipio, que los bizantinos encontraban en las fuentes junto a spondeo, dico y que debían considerar igualmente arcaico y quiritario (19).

Lo que aparece bien claro en la constitución del 531, por lo que se refiere al receptum, es la decidida condena de su carácter abstracto en la que se funda la retórica declaración sobre lo absurdo e incompatible del instituto con las leyes y la consiguiente orden de cancelar en la compilación toda referencia a la antigua acción recepticia.

Si todo esto es cierto y se el receptum argentariorum no puede considerarse un instituto vivo en el tráfico jurídico de la época de Justiniano, se impone la necesidad de clarificar la relación existente entre la abolición del receptum y la ampliación del constitutum.

Comencemos poniendo en duda la pretendida transferencia de elementos del receptum al constitutum (20) y la influencia que ha podido ejercer el primero en la reforma del segundo (21).

Si nos planteamos, en este sentido, cuál es la razón por la que Justiniano reformó el constitutum debiti, no parece acertado hallarla ni en el hecho de que el receptum había desaparecido, ni en la necesidad de extender el constitutum a cuanto de plenius tenía el receptum (22).

El punto de partida para una adecuada interpretación de la reforma es reconocer el importante papel que el constitutum asume en las fuentes posteriores a la constitución reformadora. En ellas, el constitutum debiti alieni adquiere una posición de neta prevalencia; bajo el término griego antiphonesis encontramos regulado el negocio de garantía y el de recepción de deuda practicado por los banqueros bizantinos, los cuales recurrían, con toda probabilidad, a formas contractuales propias de su tradición jurídica (23).

Ahora bien, la transformación del constitutum no resulta de la constitución reformadora con la que, precisamente, esta transformación se debería haber producido. Las innovaciones introducidas con ella por Justiniano que, en hipótesis, deberían considerarse derivadas del receptum, no son eficaces para tal fin. En efecto, en ese largo texto, si bien son significativas las referencias al receptum como promesa pro alio, sin embargo, no se da particular relieve todavía al constitutum como forma de recepción de deudas ajenas en el campo de las garantías personales. Sobre la posibilidad de prometer pro alio se hace una fugaz referencia, incidentalmente, al tratar de la perpetuidad de la acción (24).

Pero hay más; las muy discutidas innovaciones que se deberían haber producido a imitación del receptum, es decir, los elementos que de éste deberían haber sido transferidos al constitutum, se reducen en realidad a bien poco y, precisamente, consisten sólo en la extensión objetiva de su ámbito de aplicación más allá del límite clásico de las deudas referidas a res quae in pondere numero mensura consistunt. Es, ciertamente, sorprendente que a este hecho no se le haya dado la debida 
importancia y que, por consiguiente, no se hayan extraído las debidas consecuencias que permite el examen del contenido normativo de nuestra constitución (25).

$\mathrm{La}$ afirmación que acabamos de hacer encuentra su fundamento en las siguientes razones:

1.- La plena transmisibilidad hereditaria activa y pasiva de la a. pec. const., así como la aplicación de la regla praescriptio triginta annorum, aparecen como consecuencias naturales del desarrollo histórico del negocio y de la desaparición de su originaria naturaleza penal de la que dependían las limitaciones precedentes; por ello, no pueden ser reconducidas al receptum y, para el c. deb. alieni., Gordiano había reconocido la perpetuidad y transmisibilidad hereditaria pasiva de la acción (26).

2-. Por otra parte, el reconocimiento de la validez del constitutum debiti in diem y sub condicione se debe, simplemente, al cambio de concepción de la estructura de las relaciones jurídicas condicionadas, es decir, a la admisión de la eficacia retroactiva a la verificación de condición, equiparada en este aspecto al dies en la época postclásica (27). Y, además, es decisión legislativa de cuestiones discutidas por la jurisprudencia clásica en tema de constitutum.

3.- Incluso, por lo que se refiere a la extensión del constitutum más allá de las deudas pecuniarias, es legítima la duda de que ello puede derivar del receptum argentariorum. La norma viene concebida en términos generales, admitiendo la posibilidad de garantizar por constitutum, non solum res quae pondere numero mensura sunt, sed etiam alias ommes sive mobiles sive immobiles sive semoventes sive instrumenta vel alias quascumque res, quas in stipulationem possunt homines deducere (28). Una confirmación de esto la tenemos en el Digesto, donde viene reconocida, mediante interpolación, la posibilidad de constituirse lo debido ex quocumque contractu sive certi sive incerti (29). Como vemos, ahora se habla tanto de obligaciones ciertas como de obligaciones inciertas; pero lo que resulta claro es que del constitutum de obligación incierta no tenemos ejemplo alguno. Ello nos lleva a considerar que la genérica extensión no debe tener gran importancia práctica. Y, como hemos visto, el mismo Justiniano hace referencia sólo a la hipótesis de obligación cierta.

Aun reconociendo la validez de las conclusiones anteriores, nos interesa todavía insistir en este punto concreto. Resulta muy significativo que los compiladores introdujesen en el título del Digesto dedicado al constitutum fragmentos que, originariamente, estaban referidos a receptum, como ha demostrado la crítica interpolacionista. Resulta muy significativo, porque nos hace concebir la idea de que el constitutum se nutre a consta de la desaparición del receptum argentariorum. Si nos fijamos bien, el constitutum es un negocio jurídico con un ámbito personal de aplicación generalizado, mientras que esto no resulta válido para el receptum. Nos preguntamos cuál sería entonces el modo en que opera la reforma. Creemos que se trata de engrosar, de manera artificial, el constitutum que va a acoger en su seno una institución de derecho bancario caracterizada por un régimen jurídico muy distinto del que es propio del negocio ahora ampliado. nos encontramos ante un ejemplar con dos naturalezas, ya que no hay unificación jurídica y ssólo se puede hablar de 
cambio semántico cuyo alcance parece ser más teórico que práctico. En efecto, en el Digesto se regula el constitutum como institución de derecho común y aquí ya no se hace referencia alguna a su nueva vertiente especial de derecho bancario que habría introducido la constitución del 531, mientras que el régimen de la contratación de los argentarii se desarrolla por la vía independiente de las Novelas, bajo el término de antiphonesis pura. Por otra parte, la moderna traducción del antiphonesis, en sentido general, por constitutum resulta muy descutible y sólo tiene en su apoyo los datos que suministra la constitución reformadora del 531, como ya iremos viendo. Estamos, por tanto, ante un problema terminológico que no puede ocultar las diferencias, en cuanto al régimen jurídico, entre estas instituciones, la de D. 13, 5 y la recogida en las Novelas. Pero, volviendo a la constitución reformadora, hay que saber cuál puede ser el motivo por el que constitutum y acción recepticia aparecen unidos. Sin duda, resultaba necesario encuadrar la garantía bancaria helenística dentro de alguna de las categorías ya conocidas por el Derecho romano, y para ello no se encuentra otra cosa mejor que aprovecharse de la evolución que, por su parte, estaba sufriendo el constitutum, en el sentido de ampliar su ámbito de vigencia (30).

La función de garantía que el constitutum había podido cumplir, con los mismos caracteres, en el derecho clásico, aparece ahora acentuada, sobre todo, en las fuentes justinianeas y bizantinas posteriores a la reforma del 531. Esto se explica al prevalecer en la práctica jurídica el constitutum debiti alieni respecto al constitutum debiti proprii que todavía en el Digesto aparece considerado como la forma principal, pero cuya función en el derecho clásico viene a menos en el derecho justinianeo.

En el párrafo anterior, por decirlo gráficamente, se está considerando el viejo tranco del constitutum romano injertado en la nueva savia de la antiphonesis helenística de las Novelas. Esta imagen es una consecuencia del planteamiento que, ante todo, busca establecer un parelelismo entre las instituciones del Derecho romano y las de Derecho helenístico. Planteamiento al que, sin pretender negar su interés, no podemos olvidar que, de una parte, la tradición griega viva de las Novelas y, de otra, el anquilosado constitutum del Digesto no coinciden plenamente. Las diferencias entre ellos no derivan sólo de la evolución histórica sino que son el producto del contraste de dos diversos ordenamientos jurídicos, con estructuras y principios propios. Otra cosa son los problemas planteados por la necesidad de traducir del griego al latín, y aquí sí resulta posible colocar el término constitutum por el de antiphonesis después del 531. Pero ni ésta es la única posibilidad, ni quizá sea la mejor.

En estas circunstancias, nos parece oportuno asignar al término constitutum una doble acepción, dentro del ámbito del Derecho helenístico.

1.- Como vestimenta romana de un negocio perteneciente a la tradición jurídica griega (31).

2.- Como negocio perteneciente al derecho bizantino en materia de garantía personal de las obligaciones. 
El mismo doble significado anterior podemos atribuir al discutido indefense constituere.

Las consideraciones anteriores nos permiten llegar a una interpretación sobre el significado real de la reforma del 531.

En primer lugar, vamos a recordar el contenido normativo del texto de Justiniano (C. 4, 18, 2), subrayando los términos que en este momento nos interesan especialmente:

...hac apertissima lege definimus ut liceat omnibus constituere non solum res quae pondere numero mensura sunt, sed etiam alias omnes sive mobiles sive immobiles sive semoventes, sive instrumenta vel alias quascumque res, quas in stipulationem possunt homines deducere, et neque sit in quocumque casu annalis, sed (sive pro se quis constituat sive pro alio) sit et ipsa in tali vitae mensura, in qua omnes personales sunt actiones, id est in annorum metis triginta: et liceat pro debito puro vel in diem vel condicionali constitui: et non absimilem penitus stipulationi habeat dignitatem, suis tamen naturalibus privilegiis minime defraudata: sed et heredibus et contra heredes competat, ut neque recepticiae actionis neque alio indigeat res publica in huiusmodi casibus adminiculo, sed sit pecuniae constitutae actio per nostram constitutionem sibi in omnia sufficiens... hoc tantummodo constituatur, quod debitum est, et omnia, quae de recepticia in diversis libris legislatorum posita sunt, aboleantur et sit pecunia constituta omnes casus complectens, qui et per stipulationem possint explicari.

El fin peseguido por nuestra constitución es la extensión del ámbito de aplicación de la actio pecuniae constitutae. En efecto, en la compilación resulta alterada la típica función que el edicto de pecunia constituta había cumplido en el sistema clásico. Los bizantinos nos presentan una acción reipersecutoria y el constitutum debiti como una promesa de pago, es decir, como una figura contractual cuyo objeto es el cumplimiento de una prestación ya debida por una causa precedente y paralela a la stipulatio debiti.

Resulta significativa la insistencia con que en la constitución del 531 se hace referencia a la stipulatio, lo que nos confirma que es en ésta, precisamente, y no en el receptum (32), en la que el emperador está pensando al suprimir las antiguas limitaciones del constitutum. Lo que se persigue es la plena equiparación de esta figura pretoria con la general forma contractual civil (33).

Probablemente, esta equiparación con la stipulatio se enmarca dentro del proceso de evolución degenerativa de la obligatio verborum, en el que decae su típico requisito formal de la oralidad. $\mathrm{Y}$, por lo que se refiere al requisito de la presencia de las partes, como es sabido, venía siendo posible un simple reconocimiento, ordinariamente escrito, de haber realizado el acto, admitiéndose la prueba en contrario dentro de muy restringidos límites (34). En el sistema del derecho justinianeo, en el que el carácter formal de la estipulación se reduce sustancialmente al animus stipulandi y, al mismo tiempo, vienen atenuados los efectos rigurosos de su carácter abstracto, respecto a la causa praecedens, el paralelismo aparece tan acusado que hace muy difícil discernir cuándo estamos ante una stipulatio y cuándo ante un constitutum (35). 
En suma, el reconocimiento de la posibilidad de asumir por constitutum todo tipo de prestaciones no derivaría de su pretendida fusión con el receptum, sino que encontraría su apoyo en la interpolación del texto del Digesto 13, 5, 1, 6, en el que viene proclamada la general aplicación del instituto para cualquier débito, ex quacumque causa - id est ex quocumque contractu sive certi sive incerti (36).

\section{2.- Alcance práctico de la reforma.}

La principal nota característica de la evolución de la garantía personal en el derecho postclásico y justinianeo puede expresarse mediante el término simplificación (37).

En lugar de aquella multiplicidad de instituciones propia del derecho clásico (38), subsiste ahora, únicamente, la fideiussio (39). Se considera esta fideiussio, de época tardía, dilatada hasta cubrir casi el concepto de garantía personal. Por el contrario, la fideiussio, en el sentido restringido de los clásicos, corresponde a una concepción de la garantía en una sociedad que tiene gran necesidad del crédito y que por ello ha dado gran impulso a la elaboración del correspondiente concepto jurídico. Esta idea está presente en el pensamiento de los juristas clásicos que elaboran los principios que han de llevar de la antigua sponsio a la accesoriedad, concorde con la nueva fideiussio. Aunque muchas normas sean comunes a los tres tipos de garantía, también es cierto que sponsio y fidepromissio se revelan arcaicas en su estructura (40).

La exposición de este sistema clásico, que debe tener en cuenta una multiplicidad de posibilidades, ha de resultar complicada. Ahora bien, cuando, posteriormente, las normas propias de la fideiussio comienzan a prevalecer en las mismas fuentes clásicas, llegadas a nosotros a través de la manipulaciones de la práctica y de las escuelas de Occidente y Oriente, tenemos una simplificación del cuadro y, en consecuencia, queda aligerada la labor del reconstructor.

En efecto, la posición preponderante que llega a asumir la fideiussio, en el ámbito de la garantía personal, es el fruto de una evolución que va incluso más allá del periodo considerado como propio del Derecho romano. Por el contrario, la concepción clásica da al problema de la garantía del crédito amplios confines y una gran riqueza de soluciones. De aquí deriva la variedad de institutos que en el derecho clásico operan en este campo: en un mundo económico en el que la labor de los juristas da impulso a la circulación del crédito, fideiussio, fideiussio indemnitatis, mandato de crédito, constitutum debiti, receptum argentariorum y otros institutos relacionados con la garantía forman un amplio abanico que se abre ante nuestros ojos.

La desaparición de esta rica articulación no sería más que el reflejo, sobre el terreno jurídico, de la crisis de la estructura social y del sistema económico. Por ello, el término simplificación no resulta totalmente exacto. En efecto, no se trata de eliminar lo que en el sistema clásico podía ser considerado como sobrante o incluso arcaico; más bien, podemos decir que en la evolución del Derecho romano, a partir del siglo IV, dichos institutos están presentes en la literatura jurídica, pero no encuentran más que modesta respuesta y mal entendimiento en la práctica (41). 
Si lo anterior es cierto, consideramos que, en esta materia de reforma de las garantías personales, no sería la práctica la que habría movido al legislador; la intervención de éste habría venido solicitada por exigencias sistemáticas, manifestadas en el curso de las labores de compilación, en la revisión de las antiguas fuentes de las que se quería conservar lo más posible, compatibilizándolo con la inteligencia y la comprensión de las nuevas generaciones (42).

Vamos a intentar poner de manifiesto, en las próximas líneas, cómo es, sobre todo, sistemático y escolástico más que práctico el resultado de la reforma. Pero también esta nueva visión teórica no surge, exclusivamente, de la simple reflexión, pues está pensada para cubrir las necesidades planteadas por la evolución del derecho helenístico a través de las Novelas (43).

Para concretar esas ideas, en el tema de la valoración de la reforma del 531, es preciso que llevemos a cabo el análisis de la misma desde las siguientes cuestiones:

1.- ¿Es posible un constitutum referido a deuda condicionada?.

2.- ¿Cuál es el tiempo de prescripción de la a. pec. const.?.

3.- ¿Es transmisible la a. pec. const. a los herederos y contra los herederos?.

4.- ¿Es posible un constitutum referido a deuda inexistente?

5.- $¿$ Es posible un constitutum referido a deuda en cuyo objeto figuren cosas distintas de las que in pondere numero mensura sunt?.

Antes de entrar en cada una de estas cuestiones, hay que tener en cuenta que la constitución va dirigida a considerar los caracteres de la actio pecuaniae constitutae. Afronta los problemas no desde un punto de vista sustantivo sino procesal. En otras palabras, tiene un estilo conforme a los esquemas que, en la época de Justiniano, debían ser conocidos sólo por quienes estaban familiarizados con los iura. Esta primera observación nos hace pensar más en un interes escolástico que verdaderamente práctico de nuestra constitución.

Comencemos por el número que trata de la posibilidad de constituir un débito bajo condición: ...et dubitaretur, si pro debito sub condicione vel in diem constituto pecunia contracta valeret. Que en el derecho clásico se admite, sin discusión, la posibilidad de constituere debitos in diem, viene probado por D. 13, 5, 3, 2 y por D. $13,5,4$ (44). Por ello no se alcanza a comprender la dubitatio a que se refiere el texto imperial. De otro modo se presentan las cosas en tema de relaciones obligartorias condicionadas, para las cuales la noticia de discusiones encuentra credibilidad por la agitada historia que este tipo de relación ha tenido en Derecho romano. También sabemos que la cláusula condicional sufre un profunda alteración en el periodo postclásico (45). Ahora bien, si nos referimos a la fórmula clásica de la actio pecuniae constitutae, se presenta como legítima la duda de poder constituere un débito condicional. Pero esto ya no es así si se piensa en los princinpios postclásicos, con arreglo a los que la condicio se ha convertido en una cláusula extrínseca del negocio, siendo equiparada a estos efectos al dies. La duda, por consiguiente, no puede venir de estos ambientes que reflejan el derecho romano tardío. Parece que está muy próximo a la verdad el pensar que esta duda vendría planteada 
en centros en que objeto de estudio eran las obras de los clásicos, especialemente de los útimos clásicos, entre los cuales la construcción del negocio condicionado había alcanzado la suficiente madurez para justificar un reexamen del problema de constituere una relación sub condicione (46).

La cuestión planteda en el número 2 viene expresada en el texto imperial en los siguientes términos: neque in omnibus casibus longaeva sit constituta (actio), sed in speciebus certis annali spatio concluderetur. La solución dada por Justiniano es la siguiente: et neque sit in quocumque casu annalis, sed (sive pro se quis constituat sive pro alio) sit et ipsa in tali vitae mensura, en qua omnes personales sunt actiones, id est in annorum metis triginta...

Para una recta valoración de esta frase, conviene recordar algunos principios de la actio pecuniae constitutae del período formulario. Esta, según la opinión hoy prevalente (47), tiene naturaleza penal, al menos originariamente, y es anual. Es acertado, según los textos clásicos, que el desarrollo histórico del instituto y, en particular, la posibilidad de una constitutum debiti alieni han acentuado la función reipersecutoria de la actio que, precisamente por esto, en tales casos, ha dejado de tener naturaleza penal (48). Fundamental para este punto es D. 13, 5, 18, 2.

Función penal o reipersecutoria de la acción; anualidad o el tiempo propio de la prescripción de la acción son temas conocidos y, diremos, queridos por la última jurisprudencia clásica. Para ésta, el desarrollo de la cognitio extra ordinem, en el ámbito penal y en el civil, agravó ciertos poblemas al no coincidir en muchos puntos con el proceso formulario. En efecto, si hay una esfera del Derecho para la que el paso a la época constantiniana ha señalado una decisiva diferencia en relación al periodo precedente, ésta es la de la prescripción de la acción (49).

La prescripción teodosiana, y sus desarrollos, ha acentuado este movimiento de diferenciación, ofreciendo a la práctica nuevos problemas. Y, como sabemos, de la anualidad de la acción pretoria se pierde toda huella en las fuentes postclásicas (50).

Las premisas que hemos establecido son importantes para expresar un juicio sobre lo que C. 4, 18, 2 nos transmite, en las frases citadas, sobre el punto 3; aquí se puede concluir como en el precedente. Nos encontramos frente a una cuestión que tiene mayor probabilidad de reflejar disputas antiguas perpetuadas por nuevos exégetas que dudas debidas a cuestiones actuales. Para confirmar esta conclusión debemos fijarnos en el inciso puesto entre paréntesis; del mismo puede deducirse que la prescripción varía según se trate del c. debiti proprii o debiti alieni; según se ha mantenido, El caso del constitutum debiti alieni sería un supuesto en el que la acción perdía sus caracteres originales de penalidad y anualidad.

La cuestión recogida en el número 4 ha dado lugar a una interpretación según la cual Justiniano rechaza la tesis de quien trataba de atribuir al constitutum, sobre el ejemplo del receptum recogido a este propósito, la naturaleza de negocio abstracto.

Si lo anterior es cierto, esta decisión imperial entraría en la lucha mantenida por Justiniano contra la teoría del negocio abstracto (51). Ello viene recogido en los siguientes términos: cum satis absurdum et tam nostris temporibus quam iustis legibus contrarium est permittere per actionem recepticiam res indebitas con- 
sequi et iterum multas proponere condictiones, quae et pecunias indebitas et promissiones corrumpi et restitui definiunt.

La frase es significativa; quien aquí escribe conoce bien el fragmentarse de la unitaria condictio clásica en una multiplicidad de condictiones. Conoce incluso la figura de la condictio liberationis. Si leemos esta frase a la luz de cuanto la compilación testimonia en tema de multae condictiones y de condictio liberationis, parece justificado ligar la polémica de la cancillería imperial con las divergencias entre los maestros bizantinos que comentaban los textos clásicos. Además, el juego conjunto del aspecto sustantivo y procesal, por el que quien ha emitido la declaración de pagar, debe hacerlo, porque es verdadero deudor, aunque después pueda condicere esto que ha pagado, corresponde a una sistemática jurídica conforme a las concepciones romano-clásicas.

Finalmente, en el número 5 tenemos la extensión del constitutum más allá de las deudas en cuyo objeto figuran las res quae in pondere numero mensura sunt. Justiniano, después de haber proclamado que la razón de su innovación extensiva es la convertibilidad en dinero de todas las cosas, defiende la nueva norma invocando lo que se puede leer in libris iuris auctorum et in alia antiqua prudentia. El silencio sobre la nueva función asumida, ya antes de Justiniano, por el constitutum, al prevalecer la aplicación del c. debiti alieni, es un significativo testimonio de que las controversias de C. $4,18,2$ pertenecen a ambientes que estudian el Derecho más sobre la autoridad del pasdo que sobre la realidad del presente.

De los apartados anteriores podemos deducir que C. 4, 18, 2 no va encuadrada, propiamente, en el desarrollo que el constitutum debiti puede haber tenido en la vida efectiva del Derecho de la parte oriental del imperio; propone cuestiones que encuentran su encaje en los últimos desarrollos clásicos, pero que seguían vivos en la época de Justiniano, únicamente, en discusiones en las escuelas jurídicas. En efecto, el que C. $4,18,2$ pertenezca al grupo de las que Justiniano define (52) ad commodum propositi operis pertinentes nos advierte de que nos encontramos frente a una constitución dirigida a enmendar el ius antiquum.

Pero, además, aun reconociendo la validez de estas conclusiones, no podemos dejar de considerar el parágrafo 2 de nuestra constitución. En el mismo encontramos, como es sabido, una referencia explícita a propósito de los banqueros y, en general, de los negotiatores, mencionándose el constitutum hecho indefense en los siguientes términos: His videlicet, quae argenti distractores, et alii negotiatores, indefense constituerint, in sua firmitate secundum morem usque adhuc obtienentem durantibus.

Esta disposición abre la puerta a la evolución del derecho bancario helenístico, con posterioridad a la reforma, a través de la legislación introducida por las Novelas.

Nos interesa ahora entrar en el estudio del desarrollo histórico, en el mundo helenístico, del negocio bancario.

Para ello partimos de la Novela CXXXVI y del Edicto IX que responden al título De argentariorum contractibus (53). 
La primera de estas fuentes se refiere a la institución de la antiphonesis, en concreto, con independencia de otras formas de garantía, mientras que el Edicto IX nos proporciona datos sobre la práctica de una de sus modalidades, la antiphonesis pura probablemente muy frecuente.

El término antiphonesis es la sustantivación del verbo que significa, en general, responder a un formulación previa; en sentido jurídico se utiliza para designar una forma de garantía, es decir, el hecho de responder por otro. Este término, que sólo aparece en las Novellae (54) y que no es expresión tradicional en derecho griego (55), ha sido traducido al latín, modernamente, por constitutum (56), mientras que el receptum argentariorum vendría designado con otros términos griegos.

Ahora bien, la traducción de antiphonesis por constitutum se debe a lo establecido en la constitución reformadora, ya conocida, en la que se habla de la abolición del receptum y se dibujan nuevos perfiles para el constitutum. Dicha traducción, sin embargo, resulta discutible. En efecto, el Authenticum traduce antiphonesis por sponsio sin que ello pueda equivaler al sentido técnico en derecho clásico. Solamente en una ocasión la traduce por pecuniam constituerit vel spoponderit (57); $y$ en otra por quae fideiussa (58).

Por tanto, no se puede dar a la cuestión terminológica una importancia decisiva, pues la lengua griega no posee la exactitud del latín jurídico clásico ni la mentalidad oriental de este tiempo tiene el respeto de los juristas clásicos por las categorías conceptuales. Es preciso atender, fundamentalmente, al contenido jurídico de la institución, partiendo de lo que se nos dice en el texto.

Tras estas precisiones, vamos a definir nuestra institución. La antiphonesis pura del banquero consiste en la aceptación por éste de una deuda, actual o futura, de su cliente, obligándose a pagar en un plazo fijado (59).

Estamos ante un negocio jurídico trilateral que requiere la presencia de tres sujetos: el cliente del banquero, es decir, el deudor (60), el acreedor y el banquero que aume el pago en un plazo determinado.

Su perfección se articula en dos momentos: una orden del cliente al banquero seguida de la aceptación, por parte de éste, frente al acreedor.

Objeto del negocio es el pago de la deuda asumida por el banquero, que puede consistir en una obligación actual o futura (61); esta deuda puede referirse a una cantidad de dinero o bien a determinadas cosas (62).

No existe una referencia expresa a la forma, según la cual el banquero debe hacer su promesa al acreedor, aunque se debe pensar en un compromiso redactado por escrito. Ahora bien, por el Edicto IX pr. sabemos que la orden del cliente al banquero es hecha, a veces, por escrito (63), pero en otras ocasiones, por confianza hacia el contratante, sin ningún escrito (64), mientras que el en capítulo I se dispone que la demanda ha de ser escrita (65). En definitiva, hay que pensar que cuando la orden del cliente no constase por escrito existirían serios problemas para los banqueros en lo relativo a la obtención del reembolso.

En virtud de este negocio, el banquero queda obligado a pagar la deuda del cliente. Podemos considerar su promesa como abstracta (66), es decir, independien- 
te de la obligación del deudor principal que es su causa. El acreedor no debe probar la existencia de la obligación principal, ni el banquero pude oponerle excepciones derivadas del negocio subyacente (67), cuando se le exija el cumplimiento de la obligación.

Por consiguiente, no estamos ante un garante accesorio, un deudor añadido, como el fideiussor romano a quien se transmitían las excepciones del deudor principal (68); estamos, pues, ante un garante independiente como corresponde a la tradición griega (69). Pero esta independencia del banquero es más acusada que la del garante de la tradición griega, porque éste debía pagar si la persona por la que había salido garante no obsevaba la conducta prevista (70), mientras que el banquero venía obligado a pagar una deuda que incluso podía no ser exigible frente al deudor principal (71).

Lo anterior viene confirmado por el hecho de que el banquero podía ser demandado por el acreedor sin necesidada de haber ido previamente contra el deudor principal. Esto se opone al beneficium excussionis de la Novela IV. Pero la garantía bancaria estaba espresamente excluída de esta norma. En efecto, se puede dudar del sentido de lo que establece la Novela IV (72), porque puede significar que las garantías bancarias vendrán sujetas al nuevo orden (73) o permanecerán sujetas al orden existente (74); pero la Novela CXXXVI establece, de forma inequívoca, que el colegio de los banqueros venía excluído de la Novela IV (75). Esto da lugar a la protesta de los banqueros cuya contestación viene establecida por la Novela CXXXVI, con la que los mismos son admitidos a pactar la renuncia al beneficio de excusión (76), cuando hayan dado dinero en concepto de mutuo y hayan recibido garantes del mutuarario. Pero cuando el garante es un banquero el acreedor se dirige, en primer lugar, a él, en virtud se su solvencia y del carácter abstracto de su promesa.

Y aún hay más; en el Edicto IX, en el prefacio, se nos dice que los deudores por el hecho de asegurar su deuda reciben los documentos y recibos (77), es decir, al menos en la práctica, los acreedores liberan a los deudores principales desde el momento en que el banquero asume el pago. Estamos ante una promesa abstracta que, procedente de alguien tan solvente como el banquero, equivale para los acreedores a un pago diferido (78).

El problema para los banqueros se centra en la obtención del reembolso con respecto al deudor principal, pues si la obligación asumida por el primero no llega a nacer debe, pese a todo, pagar, no pudiendo oponer ni la querella ni la exceptio non numeratae pecuniae ni ninguna otra excepción (79).

Y el cliente deudor puede rechazar la reclamación del banquero alegando la inexistencia de la deuda (80).

A resolver las dificultades que se plantean por esta razón viene el capítulo I del Edicto IX que establece un doble sistema. En efecto, del texto en cuestión se deduce lo siguiente:

1.- Si la orden del cliente al banquero ha sido formulada por escrito, dicho cliente viene obligado, sin más, al reembolso con arreglo a lo establecido en el documento (81). 
2.- Pero si aquélla no ha sido formulada por escrito es preciso recurrir a los medios generales de prueba establecidos (82), para constatar que la garantía ha surgido por voluntad del deudor (83); en este sentido se requiere el transcurso de un plazo preestablecido en la ley, durante el cual el deudor no haya expresado ninguna queja al respecto (84).

En suma, en el supuesto de orden del cliente al banquero por escrito, el reembolso sería abstracto al igual que lo era la promesa del banquero; y en el supuesto de no haber sido fijada por escrito el reembolso sólo es abstracto desde el momento en que el banquero haya probado el encargo del deudor, con arreglo a los requisitos que ya hemos mencionado (85).

Finalmente, el deudor principal, como se desprende del capítulo II del Edicto IX, venía también obligado a pagar al banquero la retribución prevista. Para la prueba de este pacto se podría recurrir a los documentos o a los testigos. Aunque el texto no llega a establecer una presunción iuris tantum de onerosidad, subraya al menos al carácter inhabitual de la gratuidad (86).

\section{NOTAS}

1.- Es una de las leges ad commodum propositi operis pertinentes. Sobre estas constituciones, distintas de las quinquaginta decisiones, véase, LONGO, Contributo allo studio della formazione delle Pandette, BIDR, 1907, p. 145 s. DE FRANCISCI, Nuovi studi intorno alla legislazione giustinianea durante la compilazione delle Pandette, BIDR 1910, p. 155 s.; 1911, p. 186 s.; 1915 , p. $5 \mathrm{~s}$.

2.- Hemos de recordar, en este sentido, también la Paráfrasis de Teófilo.

3.- LENEL, EP, 1927, p. 132 s., quien aquí se mantiene fiel a la literatura antigua y moderna que ha hablado, genéricamente, de fusión o de ampliación del constitutum debido a la abolición del receptum.

Sin embargo, el análisis de las innovaciones introducidas con la constitución del 531 suscita dudas sobre la veracidad de las afirmaciones del Justiniano en lo referente al traspaso de elementos del receptum al constitutum, así como respecto a los motivos que hicieron posible la reforma.

4.- Ahora bien, esta opinión desconoce la sustancial diferencia entre el régimen jurídico del constitutum y el del receptum en derecho clásico. En efecto, entre ellos existirian importantes diferencias como en lo referente a la fijación de un dies certus solutionis, que no se exigiría en el receptum, o en la limitación al único supuesto de aceptación de un débito ajeno, que no es el caso del constitutum que surge y se desarrolla como constitutum debiti proprii y sólo en un segundo momento, y raramente, se admite en la hipótesis de un debitum alienum; sobre todo, en tema de la necesidad de existencia de un vínculo obligatorio previo, de una pecunia debita: mientras que en el caso de aceptación de una responsabilidad ex recepto, el banquero haría surgir una obligación autónoma y abstracta, en base a la cual el destinatario de la promesa podría dirigirse para obtener el pago et si quid non fuerat debitum.

5.- ASTUTI, Il costituto, 1941, p. 289. FREZZA, Le garanzie, 1962, p. 283.

6.- También Teófilo habla de ella como de cosa perteneciente al pasado e inusitada, Paraphr. ad 8 I. 4, 6. Incluso en el tratado helenístico prejustinianeo De actionibus. FERRINI, Sull'opuscolo greco intitolato De actionibus I, 1893, p. 366 s. llega a suponer ya producida la desaparición de la acción recepticia que falta en el catálogo.

7.- LENEL, Beiträge, 1881, p. 69. PARTSCH, Der Ediktale, ZSS 29, p. 415. CUQ, Manuel, 1928 , p. 515. 
8.- LENEL, Beiträge, cit., p. 68 s., no admite que la causa de la reforma sea el no uso del receptum.

Este autor mantiene que la fusión de constitutum y receptum habría determinado, en la práctica del mundo helenístico, la desaparición de la acción recepticia, ya que no serviría la dualidad de acciones derivada de un mismo negocio. La reforma habría consistido en la desaparición del medio procesal, pero no en la del negocio que habría sobrevivido en el mundo oriental fundido, desde el punto de vista externo, con el constitutum, en cuanto al nomen iruis. El más riguroso régimen del antiguo receptum se habría mantenido hasta Justiniano y, a pesar de la abolición formal del mismo, inciden en este mismo régimen jurídico disposiciones especiales contenidas en las Novelas aplicables a la garantía de los argentarii.

En este sentido, PARTSCH, Der Ediktale, cit., p. 412 s. (donde pone de manifiesto sorprendentes analogías entre receptum e institucines griegas) ha planteado el tema del origen del receptum argentariorum, llegando a la conclusión de que éste se encuentra en el derecho griego, considerando también que el receptum fue introducido en el Edicto del Pretor en el siglo II a. d. C. Este autor considera que el receptum es un instituto vivo en la época de justiniano y explica el tema de su abolición por las aspiraciones de los banqueros bizantinos que pretendían obtener una regulación menos rígida y gravosa de sus obligaciones, lo que viene recogido en el proemio del Edicto IX.

También PEROZZI, Ist., 1928, p. 237, considera que el receptum se ha mantenido en la práctica bizantina incluso después de la constitución del 531.

9.- COLLINET, Estudes historiques, 1912, p. $270 \mathrm{~s}$.

10.- COLLINET, Estudes, cit., p. 274. CUQ, Manuel, cit., p. 514.

11.- La investigación papirológica no ha llegado a resolver las incógnitas existentes en esta materia. MITTEIS, Receptum argentari, ZSS 29, p. 479 s., considera que dos casos de receptum vienen recogidos en P. Oxy. 91, 11 (a. 187), P. Oxy. 513, 36 (a. 184) y P. Flor. 43, 7. En contra PARTSCH, Arch. f. Pap. Forsch. 5, 1913, p. 490, que asocia el receptum con otros documentos como P. Petrie 3, 64 b, P. Lill. 16, P. Par. 9, 29 ?.

12.- En la constitución y en Teófilo se habla de la acción recepticia como de algo perteneciente al pasado. Este es un dato que se desprende de las fuentes de modo inequívoco. El enfoque puramente procesal que se da al tema confirma nuestra idea, si se piensa en la época en que el texto es promulgado.

13.- Del examen de estas fuentes se obtiene la evidencia de que, después de la reforma del 531 , al constitutum -antiphonesis- de los argentarii le es de aplicación una normativa específica distinta de la correspondiente al derecho común.

14.- Novela CXXXVI, pr. ... ut aut ipsi (argentarii) quoque communium legum participes sint, aut ne ipsis quidem constitutio nostra adversetur.

15.- Negotiatores y argenti distractores vienen considerados conjuntamente como destinatarios de esta norma. Lo mismo ocurre con c. 27 pr. C. 8,13 , mientras en c. 1 pr. 3 C. 12,34 vienen excluidos de la militia sólo los negotiatores exceptis argenti distractoribus, a los cuales se les concede una posición más favorable (Nov. IV, c. 3, 1).

En definitiva, estamos ante una norma encuadrable en el derecho mercantil helenístico y no ya en el derecho común.

16.- Según ROSSELLO, Rec. arg., 1890, p. 56 el término indefense no es usado más que en este caso en el Corpus Iuris; de aquí derivaría la multiplicidad de opiniones existentes sobre el mismo y que concretamos del siguiente modo: CUIACIUS, Comment. ad Cod. 4, 18, 1758 (IX, 241, A) explica indefense, id est ita ut nulla exceptione se tueri possint. DONELLUS, Comment. at Cod. 4, 18, 2, 1765 (VII, 1000, 20) propone sustituir por inoffense, id est sine offensa legum et iuris publici, el indefense que, según él, indicando qui iudicio non defenditur no tendría sentido. MABILLE, Arg., 1874, p. 47, dice que los argentarii, en los recepta, se encuentran "sans defense". IHERING, Espíritu del DR, 4, 1891, p. 237, relaciona indefense con renuncia a toda exepción lo que equivale a una responsabilidad absoluta y abstracta. 
17.- Llegó a pensarse que el término indefense se refería a la hipótesis en que los banqueros se encontraban en la imposibilidad de invocar la exceptio excussionis, por haber renunciado a ella. CUIACIUS, Recit. Soll. in Cod. 4, 18, 2, 1758 (IX, 241). GIPHANIUS, Explanatio, 1614, p. 250. Pero a esta interpretación se opone el hecho de que el beneficium fue introducido por la Novela IV (a. 535), mientras que el término indefense se encuentra, como sabemos, en la constitución reformadora que es de fecha anterior (a. 531).

18.- Esta interpretación corresponde, en lo fundmental, con la ofrecidas por IHERING, Espíritu, cit., p. 237 y LENEL, Beiträge, cit., p. 69, los cuales entienden el indefense constituere haciendo referencia a la antiphonesis abstracta de los argentarii; tambíen PARTSCH, Der Ediktale, cit., p. 415 y BEKKER, Recipere, ZSS 3, p. 12 n. 2.

Ahora bien, esto no comporta la identificación del constitutum hecho indefense o de la mencionada antiphonesis de las Novelas y de los Edictos de Justiniano con el receptum argentariorum del derecho romano. A esta identificación se oponen los testimonios del emperador y de Teófilo. Los banqueros bizantinos practicaban formas de garantía y esquemas negociales muy similares, quizá, a la figura romana. Piénsese que ésta habría surgido a imitación de las prácticas seguidas por los "trapezitas" griegos. Pero, exactamente no de trataba del receptum, pues el emperador no lo podría haber considerado inusitado en el momento mismo en que reconocía obligaciones especiales para banqueros y comerciantes.

19.- PARTSCH, Der Ediktale, cit., p. 413 s. BEKKER, Recipere, cit., p. 2 s.

20.- I. $4,6,8$.

21.- LEONHARD, v. Constituere en PW.

22.- COLLINET, Estudes, cit., p. 270 s.; 277 s.; 288 s. Este autor da una explicación que no parece suficiente, según la cual, la a. pec. const. sería reformada para cubrir las exigencias y necesidades de todos los pueblos que vivían bajo el derecho justinianeo. Así, se regularía, modificando los textos clásicos, no solamente al constitutum romano sino incluso, y sobre todo, las formas contractuales conformes con la práctica del Oriente helenizado. De este modo, Justiniano cedería al laudable impulso de unificar el derecho, fundiendo instituciones romanas y helenísticas que, junto a la fideiussio, servían de medios de garantía. El constitutum debiti quedaría como un instituto helenístico vestido a la romana y, además, la reforma de Justiniano, en materia de garantías personales, conservaría una forma pretoria al lado de otra civil, la fideiussio.

23.- Para precisar, diremos que en las fuentes posteriores al 531 el negocio bancario viene designado como antiphonesis pura mientras que antiphonesis es término genérico que se ha venido traduciendo por constitutum, siendo la primera una modalidad de la segunda.

24.- C. 4, 18, 2 ...Sive pro se quis constituat sive pro alio... Ni siquiera se hace mención a la limitación del receptum a los banqueros, de tal manera que los intérpretes antiguos que no conocían la Paráfrasis de Teófilo lo consideraban de aplicación general como el constitutum. ROSSELLO, Rec. arg., cit., p. 59.

25.- ASTUTI, Il costituto, cit., p. 307.

26.- C. $4,18,1$. Si pro alieno debito te solututum constituisti pecuniae constitutae actio non solum adversus te, sed etiam adversus heredes tuos perpetuo competit (a. 294).

27.- Fr. Vat. 55.

28.- Véase la genérica fórmula contenida en Ed. IX proem, de Justiniano.

29.- D. $13,5,1,6$.

30.- El papel que representan en este escenario cada uno de los "personajes" podría concretarse del siguiente modo:

a) Receptum argentariorum, inusitado instituto romano que ha de se eliminado del Digesto.

b) Constitutum, institución de Derecho romano que sufre una extensión de su campo de aplicación y que, como tal, aparece recogida en el Digesto.

c) La antiphonesis pura, institución de derecho bancario helenístico, en plena vigencia, que viene siendo desarrollada por las Novelas. Es una modalidad de la antiphonesis en sentido de garantía general. 
Las dificultades que genera la confusión terminológica en este tema pueden llevar a no entender la individualidad de cada una de estas instituciones en cuanto a su naturaleza jurídica.

31.- COLLINET, Etudes historiques I, cit., p. $270 \mathrm{~s}$.

32.- ASTUTI, Il costituto, cit., p. 315.

33.- KARLOWA, Rom. R. Gesch., 1885, p. 758. PARTSCH, Der Ediktale, cit., p. 412, habla de similitud entre receptum y stipulatio, ya que el consitutum es reformado en relación con la abolición del receptum, equiparándolo a la stipulatio. También en el texto paralelo de Basílicos (26, 3, 2 HEIMB. III p. 109) se reproduce la referencia a la stipulatio, mientras del receptum no se hace mención alguna.

34.- SEGRE, Le garanzie personali, 1933, p. 269 n. 1.

35.- Una confirmación de cuanto venimos diciendo la encontramos en I. 4, 6, 9: ...de pecunia constituta cum omnibus agitur, quicumque vel pro se vel pro alio soluturos se constituerit, nulla scilicet stipulatione interposita nam alioquin si stipulandi promiserint, iure civili tenentur.

36.- LONGO, Natura actionis nelle fonti bizantine, BIDR 17, p. 34 s. y $78 \mathrm{~s}$.

37.- LEVY, Weströmisches Vulgarrecht, 1956, p. 196. KASER, Das römische Privatrecht, 1975, p. $330 \mathrm{~s}$.

38.- Gayo 3, 115: pro eo quoque, qui promittit, solent alii obligari, quorum alios sponsores, alios fidepromissores, alios fideiussores apellamus.

39.- LEVY, Weströmisches, cit., p. 56 s. y 196 s. DE MARTINO, Le garanzie, 1937-1938, p. 35 s. FREZZA, Le garanzie, cit., p. 34.

40.- FREZZA, Le garanzie, cit., p. $35 \mathrm{~s}$.

41.- ARCHI, Contributi alla critica del Corpus Iuris, BIDR 1962, p. 134.

42.- ASTUTI, Il costituto, cit., p. $315 \mathrm{~s}$.

43.- En este sentido se manifiesta FREZZA, Le garanzie, cit, p. $282 \mathrm{~s}$.

44.- ASTUTI, Il costituto, cit., p. 30 s., p. 134 s. FREZZA, Le garanzie, cit., p. 248-249.

45.- LEVY, Weströmisches, cit., p. 88 s. KASER, Das römische Privatrecht, cit., p. 64 s. ARCHI, v. "Condizione" en Enciclopedia del Diritto.

46.- ARCHI, Contributi, cit, p. 143.

47.- ASTUTI, Il costituto, cit., p. 79 s. FREZZA, Le garanzie, cit., p. 229 s. En contra VOCI, Risarcimento e pena privata nel diritto romano classico, 1939, p. 149.

48.- FREZZA, Ob. cit., p. 229 s.

49.- ARCHI, Contributi, cit., p. 144.

50.- AMELOTTI, La prescrizione delle azioni in diritto romano, 1958, p. 224.

51.- ASTUTI, Il costituto, cit., p. $281 \mathrm{~s}$.

52.- C. Cordi, I.

53.- VAN DER WAL, Manuale Novellarum Iustiniani, 1964, p. 11, ha puesto de manifiesto las dificultades para determinar la fecha de estas disposiciones.

54.- No se encuentra el término en BORTOLUCCI, Index verborum graecoum quae in Institutionibus et Digestis occurrunt, 1906, ni en MAYR, Vocabularium Codicis Iustiniani II, 1925.

55.- No aparece en BEAUCHET, Histoire du Droit Privé de la République Athénienne IV, 1887, p. $565 \mathrm{~s}$.

56.- MITTEIS, Receptum argentarii, ZSS 29, p. 479-480. SCHOLL y KROLL, Corpus Iuris Civilis III, 1954. TAUBENSCHLAG, Geschichte der Rezeption des romischen Privatrechts in Aegypten, Studi Bonfante I, 1930, p. 431 y The Law of Greco-Roman Egypt in the light of the papyri, 1955 , p. 415.

57.- Nov. CXV, 6, p. 548 línea 7.

58.- Nov. CXLVII, 2, p. 720 líneas 27 y 28.

59.- DIAZ-BAUTISTA, Les garanties bancaires dans la législation de Justinien, RIDA 1982, p. 175. 
60.- Ed. IX, pr., p. 772 línea 10.

61.- Ed. IX, pr., p. 772 línea 9.

62.- Ed. IX, pr., p. 772 línea 10.

63.- Ed. IX, pr., p. 772 línea 11.

64.- Ed. IX, pr., p. 772 líneas 11 y 12.

65.- Ed. IX, cap. I, p. 773 línea 7.

66.- DIAZ-BAUTISTA, Les garanties, cit., p. 177.

67.- Esta interpolación se basa en lo establecido en pr. p. 772 línea 28 y p. 773 líneas 1 y 2 . La abstracción se confirma por el hecho de que el pago lo efectuaba el banquero sin exigir pruebas del nacimiento de la deuda, Ed. IX, pr., p. 772 línea 17. También porque el deudor principal queda liberado en virtud de la promesa bancaria, Ed. IX, pr., p. 772 línea 16.

68.- I. 4,14 , 4; C. J. 8, 35, 11; D. $44,1,7$, 1; D. 44,1 , 19; D. 46, 1, 32; D. 2, 14, 21, 5; D. 2 , $14,27,1-2$; D. $17,1,29$ pr.; D. $34,3,5$ pr.; D. $46,3,95,12$; D. $2,15,7,1$; D. $46,1,68,2$; D. 46,1 , 15 pr.; D. 46, 1, 46 pr.; C. J. 4, 30, 12; C. J. 4, 30, 15; D. 16, 1, 16, 1; D. 16, 1, 19, 5; D. 14, 6, 7, 1; D. $14,6,9,3$; D. $39,5,24$; D. $44,1,8$; D. $12,2,28,1$.

69.- BEAUCHET, Histoire, cit., p. 462 FREZZA, Le garanzie, cit., p. 33. WOLFF, Griechisches Recht v. Recht en Lexicon der Alten Welt (Artemis), 1965. PARTSCH, Griechisches Bürgschaftrecht, 1909, p. 29 s. CANTARELLA, La fideiussione reciproca, 1965, p. 48.

70.- En la dogmática actual se podría decir que la obligación del garante está sometida a condición potestativa negativa.

71.- DIAZ-BAUTISTA, Les garanties, cit., p. 178.

72.- Novela IV, 3, 1.

73.- El Authenticum traduce in ordine moderno mansuris.

74.- SCHOLL y KROLL traducen de manera ambigua in eo qui nunc est ordine mansuris.

75.- Novela CXXXVI, pr.

76.- Novela CXXXVI, 1, p. 691 línea 21.

77.- Ed. IX, pr., p. 772 línea 16.

78.- DIAZ-BAUTISTA, Les garanties, cit., p. 179.

79.- El banquero no es un verdadero fideiussor, por lo que no puede oponer las excepciones correspondientes al deudor.

80.- Son muy problemáticas en este caso la condictio indebiti y la cesión de acciones del acreedor al banquero. DIAZ-BAUTISTA, Ob. cit., p. 181-182.

81.- Ed. IX, 1, p. 773 línea 15.

82.- Ed. IX, 1, p. 773 línea 16.

83.- Ed. IX, 1, p, 773 líneas 12 y 13.

84.- Ed. IX, 1, p. 773 líneas 10 y 11. Ello tendría lugar mediante la interposición de la querella non numeratae pecuniae del cliente frente al banquero.

85.- DIAZ-BAUTISTA, Les garanties, cit., p. 184. El banquero mediante su promesa da seguridad al acreedor de que la deuda va a ser pagada, con lo que cumple una importante función en el comercio; pero a la vez el banquero cuenta, desde el primer momento, con la posibilidad de obtener el reembolso frente al deudor principal.

86.- Ed. IX, 2, p. 773 líneas 20 y 21. VAN DER WAL, Manuale Novellarum Iustiniani, cit., p. $105 \mathrm{n} .3$, cree que se trata probablemente de una interpretación errónea de la regla mandata gratuita esse debent. En efecto, la gratuidad del mandato viene afirmada en Gayo 3, 162; D. 17, 1, 1, 4; D. 17, 1, 36, 1 y en Inst. 3, 26, (27), 13; pero no se trata de una regla absoluta. En este sentido ARANGIO-RUIZ, Il mandato in Diritto romano, 1963, p. $114 \mathrm{~s}$. 